\title{
The Impact of Demographic Characteristics and Lifestyle in the Distribution of Cystatin C Values in a Healthy Greek Adult Population
}

\author{
Angelos A. Evangelopoulos, ${ }^{1}$ Natalia G. Vallianou, ${ }^{1}$ Vassiliki P. Bountziouka, ${ }^{2}$ \\ Amalia N. Giotopoulou, ${ }^{2}$ Maria S. Bonou, ${ }^{1}$ John Barbetseas, ${ }^{1}$ Peter C. Avgerinos, ${ }^{1}$ \\ and Demosthenes B. Panagiotakos ${ }^{2}$
}

${ }^{1}$ Department of Internal Medicine, Polykliniki General Hospital, 10552 Athens, Greece

${ }^{2}$ Department of Dietetics and Nutritional Science, Harokopio University of Athens, 17671 Athens, Greece

Correspondence should be addressed to Angelos A. Evangelopoulos, aevangelopoulos@hotmail.com

Received 27 July 2010; Accepted 3 October 2010

Academic Editor: Undurti N. Das

Copyright (C 2011 Angelos A. Evangelopoulos et al. This is an open access article distributed under the Creative Commons Attribution License, which permits unrestricted use, distribution, and reproduction in any medium, provided the original work is properly cited.

Background. The aim of the present study was to examine sources of variation for serum cystatin C in a healthy Greek population. Methods. Cystatin C together with basic clinical chemistry tests was measured in a total of 490 adults (46 \pm 16 yrs, $40 \%$ males) who underwent an annual health check. Demographic, anthropometric, and lifestyle characteristics were recorded. Results. Higher values of cystatin $\mathrm{C}$ were observed among males $(P=.04)$, participants aged over 65 years $(P<.001)$, current smokers $(P=.001)$ and overweight/obese participants $(P=.03)$. On the contrary, alcohol consumption and physical activity seemed to have no influence on cystatin $C$ levels $(P=.61 ; P=.95$, resp.). Conclusions. In interpreting serum cystatin $C$ values in a healthy adult population, age, gender, Body Mass Index, and cigarette smoking need to be considered, and determination of reference ranges among distinct subpopulations seem to be prudent.

\section{Introduction}

Cystatin C is a nonglycosylated, low molecular weight $(13.250 \mathrm{Da})$, basic protein that is a member of the cystatin superfamily of cysteine protease inhibitors [1-3]. It consists of 120 amino acids, it is produced by all nucleated cells at a constant rate, and it is excreted by the kidneys by free glomerular filtration and complete tubular reabsorption and degradation [4-6]. Therefore, serum concentration levels of cystatin $\mathrm{C}$ are almost totally dependent on the glomerular filtration rate and-unlike serum creatinine levels which increase after glomerular filtration rate has fallen by approximately $50 \%$ - even a slight reduction in glomerular filtration rate causes a rise in serum cystatin $C[7,8]$. Besides its usefulness as a marker of renal function, serum cystatin $\mathrm{C}$ appears to be a prognostic marker of cardiovascular events and death among elderly persons without chronic kidney disease $[9,10]$. Therefore, it is important to establish reference values of cystatin C not only for nephrologists, but for cardiologists as well.

In this study, serum cystatin C concentrations were measured in a healthy Greek adult population, and reference intervals were derived after taking under consideration sources of variation for this population.

\section{Materials and Methods}

2.1. Participants. Between April 2009 and January 2010, a total of 490 consecutive adults (85\% participation rate), who had visited the "Polykliniki" General Hospital for an annual health check, agreed to participate in the study. The retrieved data were confidential, and the study followed the ethical considerations provided by the World Medical Association (52nd WMA General Assembly, Edinburgh, Scotland, October 2000). Moreover, the Institutional Review 
Board approved the design, procedures, and aims of the study (GA 23/14.05.2009). All participants were informed about the procedures of the study and agreed to participate providing written informed consent.

Subjects who reported chronic diseases such as renal failure, diabetes mellitus, cardiovascular diseases, cancer, thyroid dysfunctions, or pregnancy were excluded as well as those treated with drugs that may influence renal function or cystatin C concentrations (i.e., antihypertensives, diuretics, antiinflammatory agents, hypoglycemic agents, anticonvulsants, and antibiotics). Other exclusion criteria were: (1) fasting serum glucose $\geq 126 \mathrm{mg} / \mathrm{dL}$, (2) systolic blood pressure $\geq 140 \mathrm{mmHg}$ or diastolic blood pressure $\geq 90 \mathrm{mmHg}$, (3) Body Mass Index (BMI) $\leq 18.5$ or $\geq 30$, to avoid the extremes of body size, and (4) eGFR (glomerular filtration rate) $<60 / \mathrm{ml} / \mathrm{min} / 1.73 \mathrm{~m}^{2}$, a threshold defining Chronic Kidney Disease (CKD) by the independent international Kidney Disease Improving Global Outcomes Organization (KDIGO) using the simplified Modification of Diet in Renal Disease Study (MDRD) equation [11, 12]. Therefore, 279 individuals ( $40 \pm 13 \mathrm{yrs}, 37 \%$ males) fulfilled the abovementioned criteria and were found eligible to participate in the study.

2.2. Other Characteristics. Participants were classified to the following age categories: $18-44 \mathrm{yrs}, 45-64 \mathrm{yrs}$, and $\geq 65 \mathrm{yrs}$. Waist circumference and height (without shoes) were measured to the nearest $0.5 \mathrm{~cm}$, and weight was measured with a lever balance, to the nearest $100 \mathrm{~g}$, without shoes, in light undergarments. Body Mass Index (BMI) was then calculated as weight in kilograms divided by the square of standing height in meters. Participants were then classified in those with normal values of BMI (i.e., $<25 \mathrm{~kg} / \mathrm{m}^{2}$ ) and to overweight/obese (BMI $\geq 25 \mathrm{~kg} / \mathrm{m}^{2}$ ). With respect to lifestyle characteristics, participants were asked to fill in a 10-grade scale range regarding their physical activity status (grade of scale used: 1-10, where 1 denotes sedentary lifestyle and 10 daily hard activity of at least 30 minutes). Participants with score $\leq 6$ were classified as with low/moderate activity, while those with score $>6$ were considered as highly active. Alcohol consumption was assessed as the self-reported number of drinks per week and participants were categorized as never/rare (i.e., 0-1 drink/week) and current drinkers (i.e., $>1$ drink/week). Current cigarette smoking (yes, no) was also recorded.

2.3. Biochemical Characteristics. Systolic and diastolic blood pressures, together with fasting serum glucose, serum creatinine, and cystatin $\mathrm{C}$, were measured in all participants. Blood pressure was measured by the same physician using a standard mercury sphygmomanometer on the right arm of the seated subject. Venipuncture was performed for each participant, early in the morning (between 07:00 am and 11:00 am), after a 12-hour fasting period by applying a natural latex rubber strap and using a $20 \mathrm{~mL}$ syringe. Blood was immediately transferred to two tubes without anticoagulant (Greiner Vacuette, Cat. no. 455071). Samples were left undisturbed for 20 minutes to clot and then centrifuged at
4000 Rotations per Minute (Relative Centrifugal Force: RCF 2.7) for 10 minutes so as to obtain serum.

2.4. Laboratory Analyses. Glucose was determined via an enzymatic colorimetric test (glucose oxidase PAP, Trinder endpoint reaction, GOD-PAP). Serum creatinine was determined via a kinetic colorimetric assay based on the reaction of creatinine with picric acid in alkaline solution and cystatin $\mathrm{C}$ via a particle-enhanced immunoturbidimetric assay. In the latter case, human cystatin $\mathrm{C}$ agglutinates with latex particles coated with anticystatin $\mathrm{C}$ antibodies, and the aggregate is determined turbidimetrically at $546 \mathrm{~nm}$.

Reproducibility in the lab has been determined using human samples and controls in an internal protocol. For the above mentioned tests, within run and between day, coefficients of variation (CV) were less than $8 \%$. Two levels of control sera were used for these assays (Precinorm U plus 12149435122 \& Precipath U plus 12149443122 for glucose and serum creatinine, cystatin C control set 04975936190 for cystatin C). Control recovery for all tests was very close to the recommended target values ( $\mathrm{TV} \pm 5 \%$ ). Accuracy of results is further supported by participation in suitable external quality assurance program for glucose and serum creatinine (ESEAP). All measurements were performed on a Roche/Modular Analytics analyzer. Reagents, calibrators, controls, and consumables were purchased from same supplier (Roche Diagnostics GmbH, Sandhofer Straße 116, D68305 Mannheim, Germany).

2.5. Statistical Analysis. Continuous variables are presented as mean \pm standard deviation and categorical variables as absolute $(N)$ and relative frequencies (\%). Comparisons of continuous variables between groups of study were performed using the independent samples $t$-test and the Analysis of Variance, after controlling for the normality of the distribution. Associations between categorical variables were tested using the chi-square test. Distribution of cystatin C levels was presented for the 2.5th, 5th, 10th, 25th, 50th (median), 75th, 90th, 95th, and 97.5th percentile. Subgroups analyses were performed by gender, age category (i.e., 18-44, $45-64$, and $\geq 65$ years old), obesity status $\left(<\right.$ or $\left.\geq 25 \mathrm{~kg} / \mathrm{m}^{2}\right)$, current smoking (yes versus no), alcohol drinking (yes versus no), and physical activity status (low/moderate versus high). All statistical analyses were performed using the SPSS version 14 (SPSS Inc., Chicago, Il, USA).

\section{Results and Discussion}

3.1. Descriptive Characteristics. Thirty-seven percent of participants were male, while the mean age between genders did not differ $(40 \pm 14$ for males, $40 \pm 13$ for females, $P=.81)$. Differences were not observed as well in physical activity status between genders (i.e., $5.8 \pm 2.1$ for males versus $5.9 \pm 2.3$ for females, $P=.91$ ). Percentage of current smokers was similar between males $(34 \%)$ and females $(36 \%)(P=$ .79). Approximately $2 / 3$ of males and $27 \%$ of females were considered as overweight/obese $(P<.001)$, while $85 \%$ of males and $73 \%$ of females were current drinkers $(P=.02)$. 
TABLE 1: The distribution of serum cystatin C levels according to gender (i.e., males and females) and age groups, of apparently healthy participants in the study.

\begin{tabular}{|c|c|c|c|c|c|c|c|c|}
\hline & \multicolumn{3}{|c|}{ Males } & \multicolumn{5}{|c|}{ Females } \\
\hline & $18-44$ & $45-64$ & $\geq 65$ & Total & $18-44$ & $45-64$ & $\geq 65$ & Total \\
\hline \multicolumn{9}{|c|}{$\begin{array}{l}\text { Percentiles of } \\
\text { cystatin C }\end{array}$} \\
\hline Minimum & 0.50 & 0.52 & 0.83 & 0.50 & 0.52 & 0.61 & 0.74 & 0.52 \\
\hline 2.5 & 0.56 & 0.52 & 0.83 & 0.56 & 0.54 & 0.61 & 0.74 & 0.57 \\
\hline 5 & 0.63 & 0.59 & 0.83 & 0.64 & 0.60 & 0.63 & 0.74 & 0.61 \\
\hline 10 & 0.66 & 0.70 & 0.83 & 0.67 & 0.62 & 0.64 & 0.74 & 0.64 \\
\hline 25 & 0.71 & 0.73 & 0.89 & 0.72 & 0.69 & 0.71 & 0.87 & 0.70 \\
\hline 50 & 0.77 & 0.82 & 0.98 & 0.80 & 0.76 & 0.79 & 0.99 & 0.78 \\
\hline 75 & 0.87 & 0.93 & 1.07 & 0.90 & 0.82 & 0.89 & 1.04 & 0.84 \\
\hline 90 & 0.93 & 1.00 & - & 0.99 & 0.88 & 1.00 & - & 0.96 \\
\hline 95 & 1.00 & 1.14 & - & 1.07 & 1.01 & 1.07 & - & 1.01 \\
\hline 97.5 & 1.08 & - & - & 1.13 & 1.03 & 1.12 & - & 1.07 \\
\hline Maximum & 1.10 & 1.21 & 1.18 & 1.21 & 1.05 & 1.12 & 1.14 & 1.14 \\
\hline
\end{tabular}

TABLE 2: The distribution of cystatin C levels according to obesity and smoking status, of apparently healthy participants in the study.

\begin{tabular}{|c|c|c|c|c|}
\hline & \multicolumn{2}{|c|}{ Overweight/obesity } & \multicolumn{2}{|c|}{ Current smoking } \\
\hline & No & Yes & No & Yes \\
\hline \multicolumn{5}{|c|}{ Percentiles of cystatin C } \\
\hline Minimum & 0.52 & 0.50 & 0.50 & 0.52 \\
\hline 2.5 & 0.57 & 0.60 & 0.56 & 0.59 \\
\hline 5 & 0.61 & 0.63 & 0.61 & 0.64 \\
\hline 10 & 0.64 & 0.68 & 0.64 & 0.68 \\
\hline 25 & 0.70 & 0.72 & 0.70 & 0.74 \\
\hline 50 & 0.77 & 0.80 & 0.76 & 0.81 \\
\hline 75 & 0.84 & 0.90 & 0.84 & 0.92 \\
\hline 90 & 0.95 & 0.99 & 0.94 & 1.01 \\
\hline 95 & 1.02 & 1.04 & 1.00 & 1.06 \\
\hline 97.5 & 1.07 & 1.15 & 1.08 & 1.11 \\
\hline Maximum & 1.12 & 1.21 & 1.21 & 1.18 \\
\hline
\end{tabular}

3.2. Distribution of Cystatin C Levels. Cystatin C levels varied from 0.50 to $1.21 \mathrm{mg} / \mathrm{L}$ among males and from 0.52 to $1.14 \mathrm{mg} / \mathrm{L}$ among females. In addition, cystatin $\mathrm{C}$ levels were normally distributed among the 176 healthy women and 103 healthy men that comprised the studied population (Figure 1).

The distribution of cystatin $\mathrm{C}$ levels among age groups between the two genders is presented in Table 1. In general, higher levels were observed for males as compared to females in all age groups. Specifically, cystatin C varied from 0.50 to $1.10 \mathrm{mg} / \mathrm{L}$ among males aged $18-44 \mathrm{yrs}$, from 0.52 to $1.21 \mathrm{mg} / \mathrm{L}$ among males aged $45-64 \mathrm{yrs}$, and from 0.83 to $1.18 \mathrm{mg} / \mathrm{L}$ among males over 65 yrs. Among females, the cystatin C levels varied from 0.52 to $1.05,0.61$ to 1.12 , and 0.74 to $1.14 \mathrm{mg} / \mathrm{L}$, respectively, for each age group (Table 1 ). The distribution of cystatin $\mathrm{C}$ levels was furthermore examined according to obesity and current smoking status. Levels of cystatin $\mathrm{C}$ varied from 0.52 to $1.12 \mathrm{mg} / \mathrm{L}$ for participants with BMI $<25 \mathrm{~kg} / \mathrm{m}^{2}$ and from 0.50 to $1.21 \mathrm{mg} / \mathrm{L}$ for overweight/obese participants. Moreover, cystatin C levels varied from 0.50 to $1.21 \mathrm{mg} / \mathrm{L}$ for never or ex-smokers and from 0.52 to $1.18 \mathrm{mg} / \mathrm{L}$ for current smokers (Table 2). Regarding the distribution of cystatin $\mathrm{C}$ levels according to physical activity status, this varied from 0.50 to $1.18 \mathrm{mg} / \mathrm{L}$ among participants with low physical activity and from 0.52 to $1.21 \mathrm{mg} / \mathrm{L}$ among highly active participants. In addition, cystatin C levels varied from 0.52 to $1.10 \mathrm{mg} / \mathrm{L}$ among never/rare drinkers and from 0.50 to $1.21 \mathrm{mg} / \mathrm{L}$ among drinkers (data not shown here).

Differences in mean values of cystatin C levels were observed between genders, age group, smoking, and obesity status. In particular, higher values were noticed among males $(P=.04)$, older participants aged over 65 yrs $(P<$ $.001)$, current smokers $(P<.001)$, and overweight/obese participants $(P=.03)$. In contrast, cystatin $\mathrm{C}$ levels did not seem to differ regarding alcohol drinking status and physical activity status $(P=.61, P=.95$, resp. $)$ (Table 3). 
TABLE 3: Mean values and standard deviation of serum cystatin C levels among subgroups of apparently healthy participants in the study.

\begin{tabular}{|c|c|c|}
\hline & Cystatin C (mg/L) & $P$ \\
\hline Gender & & .04 \\
\hline Male & $0.82 \pm 0.13$ & \\
\hline Female & $0.79 \pm 0.12$ & \\
\hline Age group & & $<.001$ \\
\hline $18-44$ & $0.77 \pm 0.11$ & \\
\hline $45-64$ & $0.82 \pm 0.13$ & \\
\hline$\geq 65$ & $0.98 \pm 0.12$ & \\
\hline Overweight/obesity & & .03 \\
\hline No & $0.78 \pm 0.12$ & \\
\hline Yes & $0.82 \pm 0.13$ & \\
\hline Current smoking & & .001 \\
\hline No & $0.78 \pm 0.12$ & \\
\hline Yes & $0.82 \pm 0.13$ & \\
\hline Alcohol drinking & & .61 \\
\hline 0-1 drinks/week & $0.80 \pm 0.13$ & \\
\hline$>1$ drinks/week & $0.79 \pm 0.13$ & \\
\hline Physical activity & & .95 \\
\hline Never/rare & $0.80 \pm 0.12$ & \\
\hline High activity & $0.80 \pm 0.13$ & \\
\hline
\end{tabular}

Various physiological sources of variation for serum cystatin $\mathrm{C}$ such as age, gender, BMI, cigarette smoking, and alcohol consumption have been reported based on analysis of healthy adult populations. Most studies have shown agerelated differences in serum cystatin $\mathrm{C}$, demonstrating that its levels increase with age [13-17]. Indeed, recent studies define reference values separately for adults and for older individuals. These studies have documented a variation in cystatin $\mathrm{C}$ levels as a function of age, probably due to the physiological aging of renal function [18-20]. In this study, higher values were noticed among older participants aged over 65 yrs $(P<.001)$.

Gender differences in cystatin $C$ levels have not been consistently observed. Such differences were significant in some studies, especially for adults below 60 years of age [20$22]$, but not significant in others $[13,23]$. In this study, gender differences in cystatin $\mathrm{C}$ were revealed, with higher values of cystatin $\mathrm{C}$ among males as compared with females.

The findings of this study, regarding the influence of smoking in the levels of cystatin $\mathrm{C}$, have been also confirmed by other studies $[13,24]$. It seems likely that smoking is an independent source of variation for cystatin $\mathrm{C}$, although the mechanism is not known.

Previous studies with respect to positive association of cystatin C levels with BMI support the above mentioned results of this study $[25,26]$. Specifically, higher values of cystatin C levels among overweight/obese individuals in comparison with normal weight individuals were revealed. Laboratory studies have examined the expression of cathep$\sin \mathrm{S}$ as a new biomarker of adiposity and have shown that human adipose tissue secretes and expresses cathepsin S,

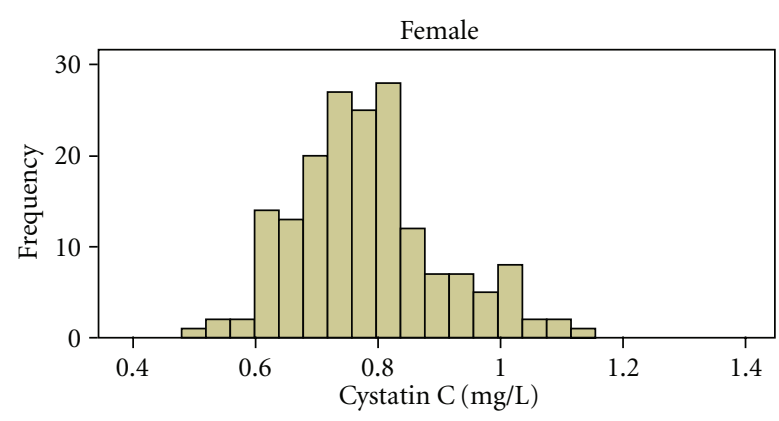

(a)

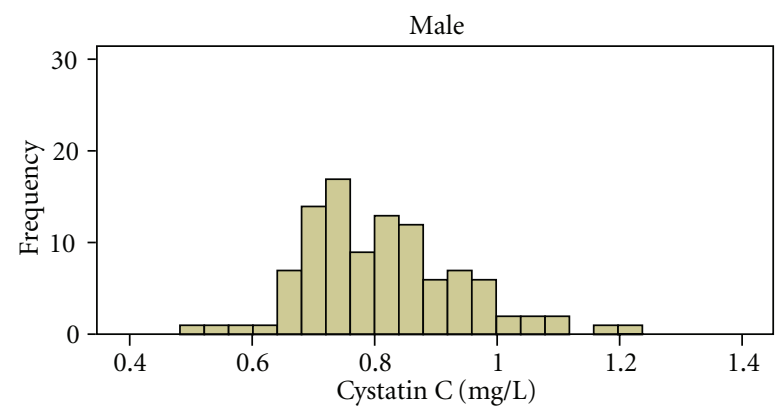

(b)

FIGURE 1: The gender-specific distribution of serum cystatin C levels among healthy participants of the study.

which is upregulated in obesity [27]. Cystatin C regulates cathepsin S activity by acting as an endogenous inhibitor. It has been found that cystatin $\mathrm{C}$ secretion increased and cathepsin $\mathrm{S}$ decreased during preadipocyte differentiation, suggesting a possible role of cystatin C in adipogenesis [28].

Alcohol consumption and physical activity did not seem to influence cystatin $\mathrm{C}$ levels in the studied population. This is in accordance with most studies that have been conducted until today $[13,29,30]$.

As it is clearly mentioned on the package insert of the commercial assay for cystatin C "Each laboratory should investigate the transferability of the expected values to its own patient population and if necessary determine its own reference ranges."

\section{Conclusions}

This is - to the best of our knowledge-the first study for determination of cystatin $\mathrm{C}$ reference values in Greek population. In the era of newly discovered properties and clinical significance of cystatin C, factors such as age, gender, $\mathrm{BMI}$, and cigarette smoking need to be considered when interpreting serum cystatin $\mathrm{C}$ values even in a carefully selected healthy adult population. Determination of reference ranges among distinct subpopulations must be taken into consideration.

\section{Acknowledgments}

The authors are, particularly, grateful to the men and women from the residence of Athens, who participated in and 
collaborated on this research. They also wish to express their gratitude to C. Katsagoni and E. Bathrellou (field investigators from Harokopio University and Polikliniki Hospital), for their substantial assistance in the enrollment of the participants. Galenica SA and the Hellenic Heart Foundation funded the study (KA00173), and therefore they would also like to thank them all.

\section{References}

[1] A. Grubb and H. Lofberg, "Human $\gamma$-trace, a basic microprotein: amino acid sequence and presence in the adenohypophysis," Proceedings of the National Academy of Sciences of the United States of America, vol. 79, no. 9, pp. 3024-3027, 1982.

[2] A. J. Barrett, M. E. Davies, and A. Grubb, "The place of human $\gamma$-trace (cystatin C) amongst the cysteine proteinase inhibitors," Biochemical and Biophysical Research Communications, vol. 120, no. 2, pp. 631-636, 1984.

[3] A. J. Barrett, H. Fritz, A. Grubb et al., "Nomenclature and classification of the proteins homologous with the cysteineproteinase inhibitor chicken cystatin," Biochemical Journal, vol. 236, no. 1, p. 312, 1986.

[4] O. Simonsen, A. Grubb, and H. Thysell, "The blood serum concentration of cystatin C ( $\gamma$-trace) as a measure of the glomerular filtration rate," Scandinavian Journal of Clinical and Laboratory Investigation, vol. 45, no. 2, pp. 97-101, 1985.

[5] E. Randers and E. J. Erlandsen, "Serum cystatin C as an endogenous marker of the renal function-a review," Clinical Chemistry and Laboratory Medicine, vol. 37, no. 4, pp. 389395, 1999.

[6] M. Abrahamson, I. Olafsson, A. Palsdottir et al., "Structure and expression of the human cystatin C gene," Biochemical Journal, vol. 268, no. 2, pp. 287-294, 1990.

[7] A. Grubb, "Diagnostic value of analysis of cystatin C and protein HC in biological fluids," Clinical Nephrology, vol. 38, no. 1, pp. S20-S27, 1992.

[8] E. Coll, A. Botey, L. Alvarez et al., "Serum cystatin C as a new marker for noninvasive estimation of glomerular filtration rate and as a marker for early renal impairment," American Journal of Kidney Diseases, vol. 36, no. 1, pp. 29-34, 2000.

[9] M. G. Shlipak, R. Katz, M. J. Sarnak et al., "Cystatin C and prognosis for cardiovascular and kidney outcomes in elderly persons without chronic kidney disease," Annals of Internal Medicine, vol. 145, no. 4, pp. 237-246, 2006.

[10] M. G. Shlipak, M. J. Sarnak, R. Katz et al., "Cystatin C and the risk of death and cardiovascular events among elderly persons," The New England Journal of Medicine, vol. 352, no. 20, pp. 2049-2060, 2005.

[11] A. S. Levey, K.-U. Eckardt, Y. Tsukamoto et al., "Definition and classification of chronic kidney disease: a position statement from kidney disease: improving global outcomes (KDIGO)," Kidney International, vol. 67, no. 6, pp. 2089-2100, 2005.

[12] A. S. Levey, J. Coresh, E. Balk et al., "National kidney foundation practice guidelines for chronic kidney disease: evaluation, classification, and stratification," Annals of Internal Medicine, vol. 139, no. 2, pp. 137-I36, 2003.

[13] M.-M. Galteau, M. Guyon, R. Gueguen, and G. Siest, "Determination of serum cystatin C: biological variation and reference values," Clinical Chemistry and Laboratory Medicine, vol. 39, no. 9, pp. 850-857, 2001.
[14] H. Uzun, M. Ozmen Keles, R. Ataman et al., "Serum cystatin $\mathrm{C}$ level as a potentially good marker for impaired kidney function," Clinical Biochemistry, vol. 38, no. 9, pp. 792-798, 2005.

[15] A. Ognibene, E. Mannucci, A. Caldini et al., "Cystatin C reference values and aging," Clinical Biochemistry, vol. 39, no. 6, pp. 658-661, 2006.

[16] E. Wasén, R. Isoaho, K. Mattila, T. Vahlberg, S.-L. Kivelä, and K. Irjala, "Serum cystatin C in the aged: relationships with health status," American Journal of Kidney Diseases, vol. 42, no. 1, pp. 36-43, 2003.

[17] E. J. Erlandsen, E. Randers, and J. H. Kristensen, "Reference intervals for serum cystatin C and serum creatinine in adults," Clinical Chemistry and Laboratory Medicine, vol. 36, no. 6, pp. 393-397, 1998.

[18] D. Fliser and E. Ritz, "Serum cystatin C concentration as a marker of renal dysfunction in the elderly," American Journal of Kidney Diseases, vol. 37, no. 1, pp. 79-83, 2001.

[19] E. L. Knight, J. C. Verhave, D. Spiegelman et al., "Factors influencing serum cystatin $\mathrm{C}$ levels other than renal function and the impact on renal function measurement," Kidney International, vol. 65, no. 4, pp. 1416-1421, 2004.

[20] M. C. Odden, I. B. Tager, R. T. Gansevoort et al., "Age and cystatin C in healthy adults: a collaborative study," Nephrology Dialysis Transplantation, vol. 25, no. 2, pp. 463-469, 2010.

[21] K. Ichihara and T. Kawai, "Determination of reference intervals for 13 plasma proteins based on IFCC international reference preparation (CRM470) and NCCLS proposed guideline (C28-P, 1992): a strategy for partitioning reference individuals with validation based on multivariate analysis," Journal of Clinical Laboratory Analysis, vol. 11, no. 2, pp. 117-124, 1997.

[22] A. O. Grubb, "Cystatin C-properties and use as diagnostic marker," Advances in Clinical Chemistry, vol. 35, pp. 63-99, 2001.

[23] D. J. Newman, H. Thakkar, R. G. Edwards et al., "Serum cystatin $\mathrm{C}$ measured by automated immunoassay: a more sensitive marker of changes in GFR than serum creatinine," Kidney International, vol. 47, no. 1, pp. 312-318, 1995.

[24] K. Ichihara, K. Saito, and Y. Itoh, "Sources of variation and reference intervals for serum cystatin $\mathrm{C}$ in a healthy Japanese adult population," Clinical Chemistry and Laboratory Medicine, vol. 45, no. 9, pp. 1232-1236, 2007.

[25] P. Muntner, J. Winston, J. Uribarri, D. Mann, and C. S. Fox, "Overweight, obesity, and elevated serum cystatin C levels in adults in the United States," American Journal of Medicine, vol. 121, no. 4, pp. 341-348, 2008.

[26] S. Vupputuri, C. S. Fox, J. Coresh, M. Woodward, and P. Muntner, "Differential estimation of CKD using creatinineversus cystatin C-based estimating equations by category of body mass index," American Journal of Kidney Diseases, vol. 53, no. 6, pp. 993-1001, 2009.

[27] S. Taleb, R. Cancello, K. Clément, and D. Lacasa, "Cathepsin $S$ promotes human preadipocyte differentiation: possible involvement of fibronectin degradation," Endocrinology, vol. 147, no. 10, pp. 4950-4959, 2006.

[28] S. Taleb, D. Lacasa, J.-P. Bastard et al., "Cathepsin S, a novel biomarker of adiposity: relevance to atherogenesis," FASEB Journal, vol. 19, no. 11, pp. 1540-1542, 2005.

[29] V. Menon, R. Katz, K. Mukamal et al., "Alcohol consumption and kidney function decline in the elderly. Alcohol and kidney disease," Nephrology, Dialysis, Transplantation, vol. 25, no. 10, pp. 3301-3307, 2010. 
[30] A. C. Baxmann, M. S. Ahmed, N. C. Marques et al., "Influence of muscle mass and physical activity on serum and urinary creatinine and serum cystatin C," Clinical Journal of the American Society of Nephrology, vol. 3, no. 2, pp. 348-354, 2008. 


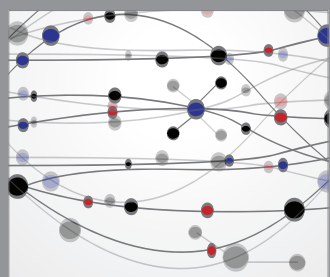

The Scientific World Journal
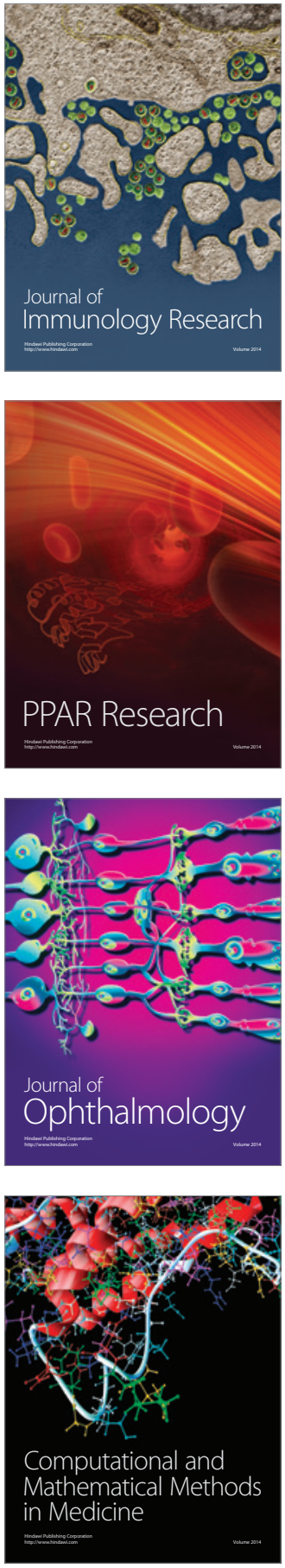

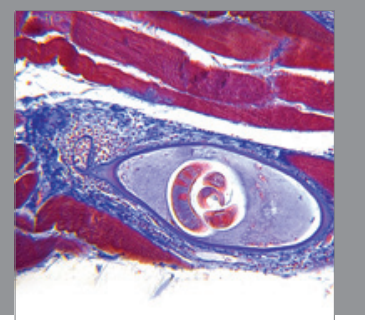

Gastroenterology

Research and Practice
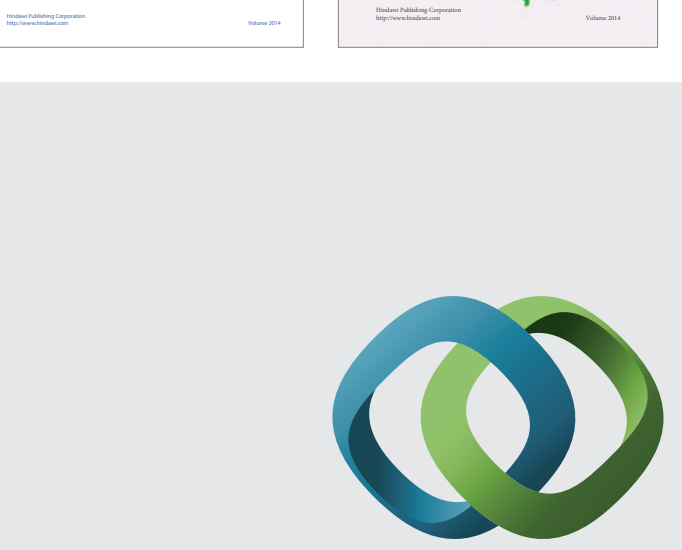

\section{Hindawi}

Submit your manuscripts at

http://www.hindawi.com
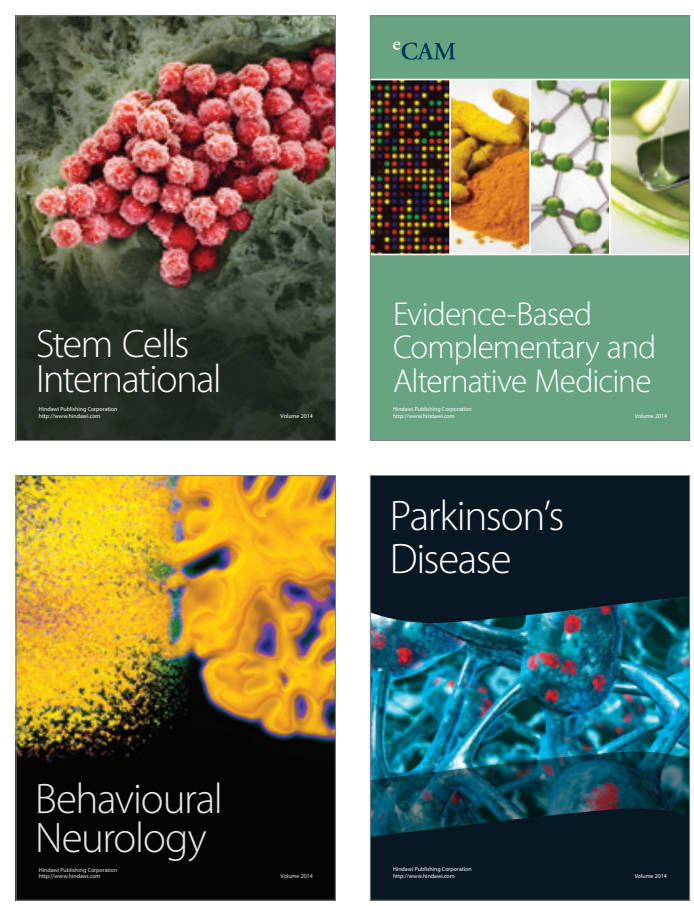

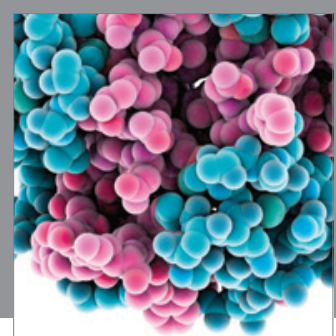

Journal of
Diabetes Research

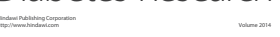

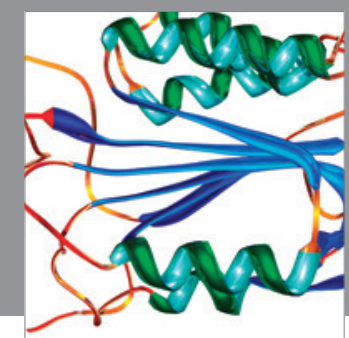

Disease Markers
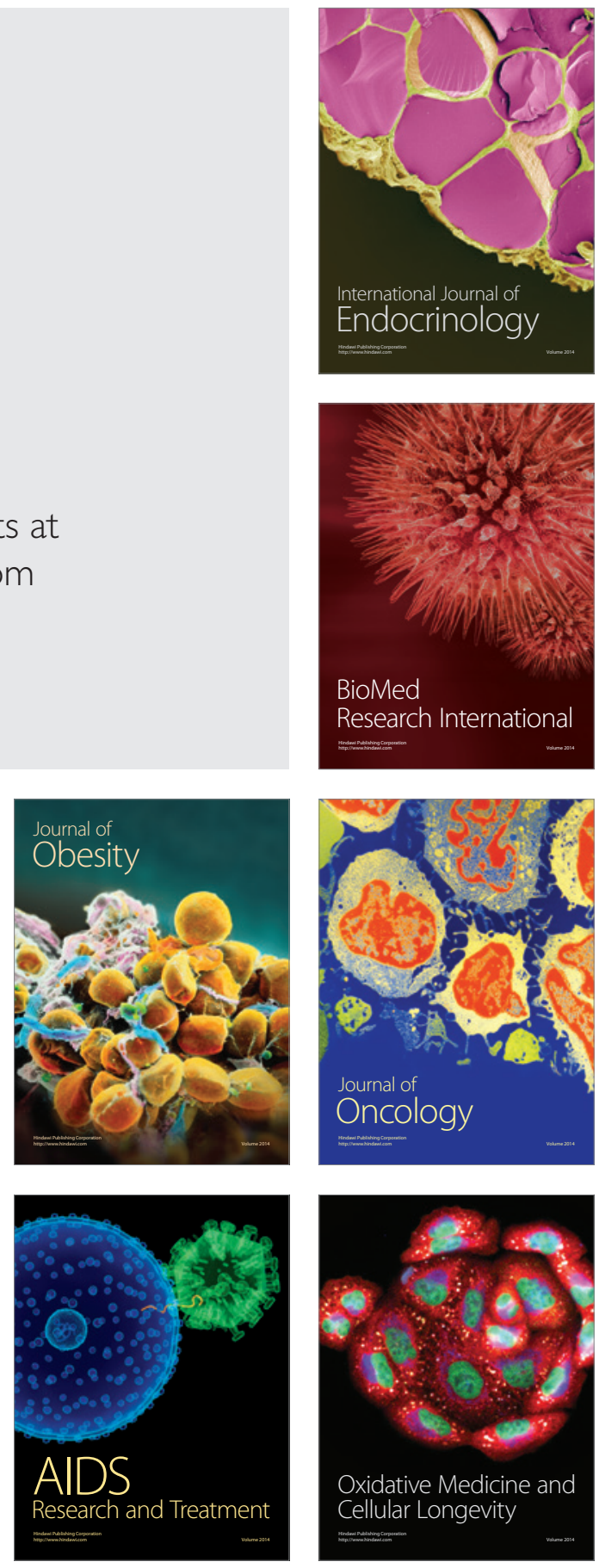